\title{
ÉLITES LOCALES CORDOBESAS DURANTE LA RESTAURACIÓN (1876-1923)
}

\author{
Ma José Ramos Rovı \\ UNIVERSIDAD DE CÓRDOBA
}

\section{RESUMEN}

Este trabajo no pretende ser, sino un punto de partida para conocer la realidad cordobesa en la época de la Restauración. Las fuentes cuya disección nos han permitido el conocimiento de los presidentes de la corporación municipal han sido los expedientes de las elecciones

municipales, los expedientes de constitución de Ayuntamientos, las Actas Capitulares, prensa, etc. Para una mejor comprensión lo hemos articulado en dos partes: en primer lugar, el marco jurídico en que se desarrollaron los comicios municipales y, en segundo, un estudio prosopográfico de los primeros ediles de la ciudad de la

Mezquita.

Tanto en los comicios generales como en los locales, en la capital cordobesa no se rompió la tónica general del país, al estar presente el reiterado protagonismo de una serie

de candidatos ministeriales que eran reelegidos por sus respectivos colegios: en ésta, como en cualquier otra urbe andaluza, sus votantes siguieron las indicaciones de su Gobernador Civil.

En la capital cordobesa se aprecia un apoliticismo de la clase media, facilitándose, con ello, la permanencia del status quo canovista. Esa docilidad hizo que el caciquismo encontrara en la ciudad

\section{ABSTRACTS}

This paper intends to settle a starting point in order to deepen in the atmosphere of Cordoba during the Restoration. Sources like municipal election files, Council foundation files, Capitular Acts or newspapers have been essential in order to have access to the identity of the heads of the municipal corporation. The present work is organised in two main parts: firstly, the juridical frame in which the municipal elections were developed and, secondly, a prosopographic study of the first councillors in the city of the Mezquita.

Both in the general elections and the local ones, the national general trend was not broken in the capital of Cordoba, due to the reiterative presence of a number of ministerial candidates who were reelected by their respective colleges: in this city, as well as in any other Andalusian metropolis, its voters followed the indications of their Civil Governor. In the capital of Cordoba, an apoliticism of the middle class is appreciated. Due to it, the permanence of the Canovista status quo is facilitated. This docility caused that a propitious atmosphere for electoral manipulation met the abuse of authority in the city of the Mezquita. 
de la Mezquita un ambiente
propicio para su manipulación
electoral.

PALABRAS CLAVES:

Historia política; prosopografía; elites locales; elecciones
KEYWORDS:

Political History; prosopography; local elites; elections

Este trabajo no pretende ser, sino un punto de partida para conocer la realidad cordobesa en la época de la Restauración. Las fuentes cuya disección nos han permitido el conocimiento de los presidentes de la corporación municipal han sido los expedientes de las elecciones municipales, los expedientes de constitución de Ayuntamientos, las Actas Capitulares, prensa, etc. Para una mejor comprensión lo hemos articulado en dos partes: en primer lugar, el marco jurídico en que se desarrollaron los comicios municipales y, en segundo, un estudio prosopográfico de los primeros ediles de la ciudad de-la Mezquita ${ }^{\dagger}$.

Antes de adentrarnos en nuestro tema de estudio, y a modo de introito, diremos que, tanto en los comicios generales como en los locales, en la capital cordobesa no se rompió la tónica general del país, al estar presente el reiterado protagonismo de una serie de candidatos ministeriales que eran reelegidos por sus respectivos colegios ${ }^{2}$ : en ésta, como en cualquier otra urbe andaluza, sus votantes siguieron las indicaciones de su Gobernador Civil.

En lo concerniente a Diputaciones y Ayuntamientos, la Constitución de $1876^{3}$ siguió a los textos anteriores, repitiendo su forma de elección, así como su organización y atribuciones a leyes particulares. No obstante, la vida

La inelegancia de la autocita podrá perdornarse mejor por la concentración de las referencias en una sola nota. Algunas de las cuestiones abordadas tangencialmente en el texto como la historia de las élites políticas y los comicios locales las hemos tratado de manera más extensa en los siguientes trabajos: $\mathrm{M}^{\mathrm{2}} \mathrm{J}$. Ramos Rovi, «Elecciones municipales en Córdoba (1875-1885)», Ambitos. Revista de Ciencias Sociales y Humanidades de Córdoba, 2 (1999), pp. 98-109. Vid. etiam «La elección de diputados a Cortes en la Córdoba de Alfonso Xll», Actas de las IV Jornadas Niceto Alcalá-Zamora y su época, Córdoba, 1999, pp. 141160. «Élites parlamentarias cordobesas durante la Restauración (1875-1902)», I Coloquio Internacional "Andalucía y el 98», Córdoba, 2001, pp. 693-714. "La vida municipal durante la Restauración (1875-1923): el caso cordobés", en AA.VV., Posada Herrera y los orígenes del Derecho Administrativo Español, Madrid, 2001, pp. 297-322.

${ }^{2}$ Tal y como se desarrollaron las elecciones del último tercio del siglo XIX, lo más llamativo del sistema político español era que el Parlamento aparecía supeditado a intereses particulares, adulterando y entorpeciendo la acción y democratización del Gobierno. Cfr. R. Macias Picavea, El problema nacional, Madrid, 1899, pp. 435-440.

${ }^{3}$ Vid. M. ${ }^{a}$ J. Ramos Rovl, «La Constitución de 1876 a través de los discursos parlamentarios», Revista de Historia Contemporánea, 9-10 (1999-2000), op. 85-100. 
municipal de la Restauración se fundamentó por un lado, en el título X, De las Diputaciones Provinciales y de los Ayuntamientos —artículos $82,83^{4}$ y 84 -, que vino a sustituir el VIII de la de 1869 y, por otro lado, en la Ley Municipal de 20 de agosto de $1870^{5}$, que fue expresamente reformada el 16 de diciembre de $1876^{6}$, en el sentido de que sustituía el sufragio universal por el censitario ${ }^{7}$, concedía al gobierno la prerrogativa de nombrar todos los alcaldes en las ciudades y los pueblos que excedieran de 30.000 habitantes, el régimen de aprovechamiento y conservación de montes quedaba nuevamente sometidos a las leyes de 1863 y al Reglamento de 1865 y, en materia de presupuestos municipales se exigía, nuevamente, la aprobación del Gobernador.

El régimen municipal y el provincial elaborado en 1876 y ordenados, en 1877, siguieron un proceso ulterior algo diferente. La Ley Municipal de 2 de octubre de 1877 continuará vigente salvo algunas enmiendas parciales ${ }^{8}$, hasta el Estatuto Municipal de 1924. En cambio, la ley Provincial de la misma fecha experimentó una reforma general el 29 de agosto de 1882, con las modificaciones esenciales que supone la ley de 11 de julio de 1912 (de Cabildos Insulares) y su reglamento de 12 de octubre del mismo año para las islas Canarias y la reforma contenida en el Real Decreto de 18 de diciembre de 1913 sobre Mancomunidades Provinciales.

Una vez visto el marco legal que rigieron las elecciones municipales de la Restauración diremos que, la organización municipal del período que nos

${ }^{4}$ El artículo 83 decía: «habrá en los pueblos alcaldes y Ayuntamientos. Los Ayuntamientos serán nombrados por los vecinos a quienes la ley confiera este derecho". J. ESTEBAN, Las constituciones de España, Madrid, 1988, p. 189.

${ }^{5}$ El proyecto de Figuerola, ministro de Hacienda, presentado el 10 de enero de 1870 se caracterizaba por un deseo de afirmar una descentralización administrativa uniforme y de base legal. Vid. A. POSADA, Evolución legislativa del régimen local en España, 1812-1909, Madrid, 1982, pp. 278-279.

${ }^{6}$ Nos referimos al Proyecto de Ley presentado por Francisco Romero Robledo, ministro de la Gobernación, que fue aprobado en la sesión del 22 de noviembre de 1876, publicándose en La Gaceta de Madrid el 17 de diciembre del mismo año. Vid. Diario de Sesiones del Congreso (en las notas siguientes D.S.C.), legislatura de 1876-1877, t. III, 24 de mayo de 1876, apéndice segundo al núm. 68. D.S.C., legislatura de 1876-1877, t. VI, 22 de noviembre de 1876, apéndice tercero al núm. 129. La Gaceta de Madrid, 17 de diciembre de 1876, núm. 352.

${ }^{7}$ Las reformas introducidas a la Ley Municipal de 17 de diciembre de 1876 concedian la emisión del voto a los vecinos de término municipal que pagasen una contribución, a los empleados civiles, jubilados o retirados del ejército y capacidades con titulo oficial. Esto quedó expresado en los siguientes términos:

Primera disposición. "Las elecciones de Ayuntamientos se ajustarán a la Ley Electoral del 20 de agosto de 1870 sin otras modificaciones que las expresadas a continuación: serán electores los vecinos cabezas de familia con casa abierta que lleven dos años por lo menos de residencia fija en el término municipal, y venga pagando por bienes propios alguna cuota de contribución de inmueble, cultivo y ganadería, o de subsidio industrial o de comercio, con un año de anterioridad a la formación de las listas electorales, o acrediten ser empleados civiles del Estado, de la Provincia o el Municipio en servicio activo, cesante con haber por clasificación, jubilados o retirados del ejército y armada.

También son electores los mayores de edad que lle-vando dos años por lo menos de residencia en el término municipal justifique su capacidad profesional o académica por medio de un título oficial». D.S.C., legislatura de 1876-1877, t. VI, 22 de noviembre de 1876, apéndice primero al núm. 129, p. 1.

${ }^{8}$ Nos referimos al Real Decreto de 5 de noviembre de 1890, La Gaceta de Madrid, 8 de noviembre de 1890, pp. 442-445. Real Decreto de 24 de marzo de 1891, La Gaceta de Madrid, 25 de marzo de 1891, p. 930. 
ocupa era uniforme y simétrica, en sus principios generales según la ley de 2 de octubre de 1877 en todo término había un Ayuntamiento y una Junta Municipal ${ }^{9}$. Ésta era una corporación compuesta por los concejales y un número igual de vocales asociados, representantes de los contribuyentes y designados anualmente por sorteo. Entre otras tenía las siguientes atribuciones: aprobación de los presupuestos, creación y establecimiento de arbitrios en la forma y tiempo legales, revisión y censura de las cuentas del Ayuntamiento, etc. El gobierno interior del municipio se encomendaba a la corporación municipal, compuesta por el primer edil, los tenientes de alcalde y los regidores.

El nombramiento de los alcaldes constituye uno de los puntos más importantes de la reforma. El artículo 49 de la ley Municipal y Provincial de 2 de octubre de $1877^{10}$ establece que «los Ayuntamientos elegirán de su seno a los alcaldes y tenientes de alcalde. El Rey podrá nombrar de entre los concejales los alcaldes de las capitales de provincia, de las cabezas de partido judicial y de los pueblos que tengan igual o mayor vecindario que aquellos dentro del mismo partido, siempre que no bajen de 6.000 habitantes... ${ }^{11}$.

El primer edil era el encargado del poder ejecutivo ${ }^{12}$ y de las funciones político-administrativas. Como representante del Gobierno, el alcalde debía desempeñar las obligaciones que las leyes le encomendaban -artículo 199-bajo la dirección del gobernador. Además de ello debía: presidir las sesiones, velar por el cumplimiento de las leyes y disposiciones superiores, publicar, ejecutar y hacer cumplir los acuerdos del Ayuntamiento, suspender la ejecución de los acuerdos de la Casa Consistorial en los casos prescritos por la ley; trasmitir a la Diputación y al gobernador los acuerdos que requirieran aprobación superior, etc.

\footnotetext{
${ }^{9}$ Cfr. arts. 29, 31, 33, 64 y 70 de la ley Municipal de 2 de octubre de 1877, La Gaceta de Madrid, 5 de octubre de 1877.

${ }^{10}$ En la elección de los alcaldes cordobeses no siempre se siguió este procedimiento. Al menos esto se desprende de la reunión que mantuvieron los ediles en el consistorio el día 6 de diciembre de 1917. «Abierta sesión pública dióse lectura por disposición de la presidencia de la Real Orden circular de 29 de noviembre anterior, inserta en el Boletín Oficial de la Provincia fecha 4 del que rige y dictada por el $\mathrm{Sr}$. Ministro de la Gobernación determinando el cese de todos los alcaldes nombrados por R.O. que desempeñen actualmente el cargo; leyéndose asimismo un oficio del Sr. Gobernador Civil, Ilamando la atención sobre el cumplimiento de lo resuelto por el ministerio mandando que se proceda a preverla vacante, en la forma prevenida por los artículos 52 y siguientes de la Ley Municipal». El resultado del escrutinio fue: Sanz Noguer, 22 votos; Mariano Salinas Dieguez, 4; Fraricisco Santolalla Natera, 1 y uno en blanco. Resultando electo para desempeñar el cargo de alcalde, para el período comprendido del 6 de diciembre al 31 del mismo mes de 1917, el primero de los ediles. Archivo Municipal de Córdoba (en lo sucesivo A.M.CO.), Actas Capitulares de 1917, sección 13.03.01, L-0471, folios 71-79.

${ }^{11}$ Fue publicada en La Gaceta de Madrid, el 5 de octubre de 1877 y en el apéndice del Diccionario de Alcubilla correspondiente al mismo año, pp. 181-401.

12 "Obviamente, un corregidor del Antiguo Régimen no es lo mismo que un alcalde en la etapa constitucional, sin embargo uno y otro tenían una misma función pública: la de ser, como magistrados locales de mayor rango, cabezas del concejo y ayuntamiento respectivamente». J. M. BERNARDO DE ARES, El poder municipal y la organización política de la sociedad. Algunas lecciones del pasado, Córdoba, 1998, p. 18.
} 
Los tenientes de alcalde estaban al frente de cada uno de los distritos en que se dividía el término municipal, sustituyendo a los alcaldes en las ausencias y vacantes, por el orden en que estuvieran nombrados, orden numérico, que no podía alterarse, conforme a lo que disponía la Real Orden de 12 de octubre de 1885. Dependientes del teniente respectivo se hallaban los alcaldes de barrio, que eran nombrados por el primer edil, y estaban al frente de los distintos colegios en los que se dividía el municipio ${ }^{13}$.

El número de concejales variaba con relación a la población de las ciudades, desde un mínimo de seis a un máximo de 50 . Para ser elegido era preciso reunir los requisitos señalados en el artículo 41 de la ley Municipal de 1877 - llevar cuatro años, al menos, de residencia fija en el término municipal, satisfacer una contribución o, bien, acreditar por medio de título oficial su capacidad profesional o académica-. El cargo de munícipe era gratuito, honorífico y obligatorio. Podían excusarse en su desempeño: los mayores de 60 años, los físicamente impedidos y aquellos que hubieran sido senadores, diputados a Cortes, diputados provinciales y concejales hasta dos años después de haber ocupado alguno de estos cargos. La elección era por cuatro años, renovándose por mitades de dos en dos $^{14}$.

Los Ayuntamientos tenían el carácter de corporación permanente. Celebraban sesiones, al menos, una vez a la semana, o bien, cuando el alcalde o el gobernador civil lo juzgara oportuno, o lo reclamaran la tercera parte de los concejales. Estas reuniones eran públicas y se celebraban en el consistorio. Tenían las siguientes funciones: establecimiento y creación de servicios municipales, conservación y arreglo de la vía pública, administración, custodia y conservación de las fincas, bienes y derechos de los pueblos, la instrucción primaria, etc.

A pesar de que los ayuntamientos gozaban de personalidad jurídica, los gobernadores podían suspender a los alcaldes y tenientes por causa grave, dando cuenta al gobierno, que alzaría la suspensión o instruiría el correspondiente expediente ${ }^{15}$. Los regidores, en cambio, no podían ser destituidos sino por sentencia judicial.

Con respecto a los candidatos también hubo algunas alteraciones. En el artículo 6 de la Ley Municipal de 1870 se especificaba que «son elegibles para concejales todos los electores vecinos de la localidad que reúnan las condiciones que exige el art. $39 »^{16}$. En el capítulo IV, «De las Incompatibili-

${ }^{13}$ Vid. los artículos 36, 58, 59, 116 y 202 de la ley Municipal de 2 de octubre de 1877, La Gaceta de Madrid, 5 de octubre de 1877 y el Real Decreto de 15 de noviembre de 1909.

${ }^{14}$ Ley Municipal de 2 de octubre de 1877, artículos 43 y ss. y de la ley Electoral de 1907, los arts. 6,7 y 8. Vid. etiam. E. Freixa y RaBASO, Elecciones por sufragio universal de diputados provinciales y concejales, Córdoba, 1881, p. 8.

${ }_{15}$ Vid. Ios artículos 189 y 191 de la ley Municipal de 2 de octubre de 1877, La Gaceta de Madrid, 5 de octubre de 1877.

${ }^{16}$ D.S.C., legislatura de 1870, 23 de junio de 1870, apéndice decimotercero al núm. 313. 
dades", se señalaba que los cargos de senador, diputado a Cortes o provincial y concejal eran incompatibles entre sí $^{17}$. Sin embargo, en la primera de las disposiciones recogida en la Ley Municipal de 17 de diciembre de 1876, se especificaba que «los cargos de senador del reino y diputado a Cortes serán compatibles con los de diputado provincial y concejal; pero estos últimos continuarán siendo incompatibles entre sís ${ }^{18}$.

Con las reformas introducidas por el Real Decreto de 5 de noviembre de $1890^{19}$, los concejales eran elegidos por los españoles varones, mayores de veinticinco años que se hallaran en pleno goce de sus derechos civiles y fueran vecinos de un municipio. Los militares y miembros de cuerpos o instituciones armadas dependientes de la Administración pública, mientras estuvieran en activo, no podían emitir el sufragio ${ }^{20}$. Con la ley Electoral para diputados a Cortes y concejales de 8 de agosto de 1907, los Ayuntamientos eran elegidos por los residentes en el término municipal, por sufragio universal, directo y secreto. Además, «las elecciones se hacían por distritos, según el criterio de voto limitado y en representación de las minorías" ${ }^{21}$. Lo lamentable del sistema era que la vida local estaba dominada por un grupo de notables sin intereses. Maura propuso la elaboración de una nueva Ley de Administración Local, que paliara, en parte, el desmedido poder de estos oligarcas $^{22}$. Sin embargo, su deseo fracasó. Tusell pone de manifiesto, que fue la inercia de una clase política instalada, unida a la escasa presión democratizadora de un electorado inmovilizado la que frustró -más allá de la retórica regeneracionista - una posibilidad concreta de apertura y consolidación de un liberalismo democrático ${ }^{23}$.

Entre 1877 y 1925 se sucedieron numerosos intentos de reforma del régimen municipal, entre ellos citaremos los de Moret (1884), Dato (1889),

${ }^{17}$ lbídem.

${ }^{18}$ D.S.C., legislatura de 1876-1877, t. V1, 22 de noviembre de 1876, apéndice primero al núm. 129, p. 2.

${ }^{19}$ Según Seco Serrano, 1890 marcó un punto de inflexión en la política de la época al conseguir Sagasta que se aprobara la Ley de Sufragio Universal. Cánovas, para no romper la continuidad esencial en la vida política del sistema de turno, aceptó las reformas democráticas del líder liberal, siempre y cuando estuviera previsto el reverso de la normativa relativa a elecciones, esto es, la manipulación electoral, Alfonso XIII y la crisis de la Restauración, Madrid, 1979, p. 24.

${ }^{20}$ En su artículo 1. ${ }^{\circ}$ dice lo siguiente: «Son electores para diputados provinciales y concejales todos los españoles varones mayores de veinticinco años que se hallen en pleno goce de sus derechos civiles y sean vecinos de un municipio en el que cuenten dos años al menos de residencia.

Las clases e individuos de tropa que sirvan en los ejércitos de mar y tierra no podrán emitir su voto mientras se hallen en las filas.

Queda establecida la misma suspensión respecto a los que se encuentren en condiciones semejantes dentro de otros Cuerpos o Institutos armados dependierites del Estado, la Provincia o el Municipio». La Gaceta de Madrid, 8 de noviembre de 1890, p. 442. D.S.C., legislatura de 1889-1890, t. XII, 11 de junio de 1890 , apéndice primero al núm. 183, p. 1.

${ }^{21}$ A. Posada, Evolución legislativa del Régimen Local en España, 1812-1909, Madrid, 1982, p. 330.

${ }^{22}$ Vid. algunos detalles de J. Tusell, La reforma de la Administración local en España (1900-1936), Madrid, 1973.

${ }^{23}$ "Los intentos reformistas de la vida política durante el reinado de Alfonso XIIl», en S. FORNER, (coord.), Democracia, elecciones y modernización de Europa. Siglos XIX y XX, Madrid, 1997, pp. 295 y ss. 
Francisco Silvela Toca (1891), Moret (1902), Maura (1903) ${ }^{24}$, La Cierva (1907) y Canalejas (1912), que persiguieron una «descentralización política y administrativa que concluirá por materializarse en el Estatuto Municipal de $1924 »^{25}$. Éste establecía la autonomía de los municipios con la posibilidad de que cada uno de ellos pudiera elaborar una Carta Municipal. Este documento debía de pasar por los cauces legales hasta ser aprobado por el Consejo de Ministros.

Como hemos podido apreciar, en el régimen local de la Restauración se advierten las preocupaciones de la época: la de la unidad política, engendrada por la acción de la tradición del absolutismo monárquico y el miedo al federalismo, y la de la soberanía concedida como un poder único, indivisible e irresistible de la nación unificada y que actuaba desde arriba o desde el centro. Por ello, se construyó «el régimen local, como función subordinada al Estado, obra suya y para sus intereses políticos. El régimen local legal español podría caracterizarse, al igual que el francés, su modelo, - como un esfuerzo para impedir las manifestaciones y movimientos del selfgovernment, regional sobre todo, y constituir una estructura políticoadministrativa uniforme, subordinada y adaptada a las exigencias de una acción centralizada - soberana- del Estado ${ }^{26}$.

Es evidente que Andalucía es la comunidad más extensa y quizá la de mejor imantación para el interés de los extranjeros y las gentes de las restantes regiones españolas. Es más, los principales capítulos y procesos de larga duración de la historia nacional se gestaron en la vasta región andaluza, banco de prueba y piedra de toque esenciales para el desenvolvimiento de múltiples episodios del ayer hispano. No podrá negarse el sobresaliente protagonismo de Andalucía en todos los caminos del pasado hispano ${ }^{27}$. En una reciente monografía sobre la historia de la capital cordobesa, publicada por Cuenca Toribio, nos pone de relieve que hasta la primera dictadura del

\footnotetext{
${ }^{24}$ El 26 de mayo de 1903, Antonio Maura y Montaner, entonces ministro de la Gobernación, presentó al Congreso un proyecto de Ley de Bases para la reforma de la administración local. Este escrito modificaría la ley Municipal de 2 de octubre de 1877 y la provincial del 29 de agosto de 1882. En opinión de Vicenti, la idea de Maura era que todos los ayuntamientos fueran fiel expresión de la voluntad de los vecinos y que gozaran de independencia y ejercieran sus funciones atentos a los intereses del municipio. No obstante, para este estudioso «los Ayuntamientos constituidos con arreglo al proyecto, representarán la voluntad del cacique amparado por el Gobierno, quedarán más supeditados al poder central que lo están los actuales y la administración que desarrollen, en general, a nadie satisfará (...) y si se quiera acabar con el caciquismo, es preciso que los municipios estén libres de las férreas manos del poder central (...). Un error, pues, querer curar los males de la administración municipal desde arriba, las leyes que se publiquen, por muy buenas que sean, resultarán ineficaces, no se aplicarán más que a los enemigos. Lo que hay que hacer es dejar a los pueblos que se administren, impedir que el cacique, prevalido del apoyo que le presta el poder, se imponga y se burle de la voluntad de los vecinos". La futura ley Municipal. Proyecto de ley de bases para la reforma de la Administración local presentado a las Cortes por el Excmo. Sr. D. Antonio Maura, Madrid, 1904, pp. 9-10.

${ }^{25}$ R. PÉrez-Bustamante, Historia de las instituciones públicas de España, Madrid, 1995, p. 205.

${ }^{26}$ A. POSADA, El régimen municipal de la ciudad moderna y bosquejo del Régimen local en España, Francia, Inglaterra, Estados Alemanes y Estados Unidos, Madrid, 1916, p. 251.

${ }^{27}$ J. M. CuenCA TORIBIO, Momentos y figuras cordobesas, Córdoba, 2003, pp. 47-54.
} 
siglo XX, la vida política discurrió en Córdoba por los cauces heredados de la etapa precedente. "Los primeros alineamientos en torno al movimiento regeneracionista se plantearon desde posiciones políticas silvelistas o desde instancias económicas con cierto eco en la provincia; los republicanos federales y fusionistas se erigieron, por su parte, en otra alternativa de renovación y regeneración política» ${ }^{28}$.

El segundo parágrafo del que nos vamos a ocupar es el de los alcaldes que estuvieron al frente de la corporación municipal cordobesa durante la Restauración (1876-1923). De los trescientos dieciséis concejales designados en las elecciones celebradas bajo el reinado de Alfonso XII, la Regencia y Alfonso XIII (1875-1923), 25 desempeñaron el cargo de primeros ediles. Esto es el 7,91 por 100.

Lo primero que llama la atención es la extensa nómina de alcaldes que tuvo Córdoba en el último cuarto del siglo XIX y las dos primeras décadas del novecientos. En total 34, lo que indica la enorme movilidad que se produce al frente del consistorio cordobés. Durante la pasada centuria la imagen del alcalde experimentó diversas modificaciones que la acercarían a los tiempos más recientes. El término "alcalde" como se entiende en la actualidad aparece por primera vez durante el Trienio liberal (1820-1823), no volviendo a recuperarse hasta junio de 1834 , al ser designado José María Trillo alcalde corregidor. En 1835, el conde de Torres Cabrera recibió el cargo de alcalde real, y en 1836, Antonio Luna García fue nombrado primer edil, denominación que ha permanecido hasta nuestros días sin apenas alteración.

No obstante, no podemos hablar del alcalde, entendido éste como órgano unipersonal de la administración local hasta 1924, fecha en la que aparece el Estatuto Municipal de Calvo Sotelo, texto que dio amplios poderes a los municipios.

Desde el punto de vista de la vida municipal hay una falta de continuidad en la presidencia de las casas consistoriales. El primer edil del sistema canovista fue Tomas Conde y Luque ${ }^{29}$. Este cordobés de 39 años de edad era de adscripción conservadora. Con Tomás Conde se inicia la andadura de una familia de gran tradición política estrechamente vinculada al progreso de Córdoba y su provincia. A modo de ejemplo citaremos a Antonio Cruz Conde., que fue el sexto alcalde de una saga que tiene sus antecedentes en

${ }^{28}$ Historia de Córdoba, Córdoba, 2002, 2." ed., pp. 197-198.

${ }^{29}$ Era hijo de José María Conde Criado, «dejo impronta en la vida política como sus sobrinos y hermanos. Sin gozar de la brillantez intelectual de su hermano Rafael, lo compensó con una entrega y dedicación completas a su ciudad natal, siendo alcalde y presidente de la Diputación. De ideología conservadora como era normal en la familia - desarrolló siempre su actividad en la gestión local, no aceptando condecoraciones y títulos que le condujera fuera de Córdoba. Murió a los cincuenta años de edad", J. PONCE ALBERCA, Del poder y sus hombres. José Cruz Conde (1878-1939). Semblanzas biográficas y perfiles ideológicos de una figura política andaluza, Córdoba, 2001, p. 32. 
Tomás, Rafael Conde Jiménez, José Cruz Conde de Fustegueras, Rafael Cruz Conde de Fustegueras, su padre y Alfonso Cruz Conde y Conde, su hermano ${ }^{30}$. El más joven de los alcaldes de la etapa Fernando Vienlant y Villanueva, marqués de Gelo, contaba tan sólo veintisiete años cuando tomó la vara de mando. El encontrarnos ediles provectos - como es el caso del togado Juan Rodríguez Sánchez, que ocupó el cargo a la edad de cincuenta y tres años-, nos hace suponer que su carrera política se cuajó en períodos anteriores.

Cuadro 1

Clasificación por intervalos de edad de acceso al cargo de concejal

\begin{tabular}{|c|c|c|c|c|}
\hline EDAD & $\begin{array}{c}\text { TOTAL } \\
\text { CONCEJALES }\end{array}$ & $\%$ & TOTAL DE ALCALDES & $\%$ \\
\hline $25-29$ & 33 & 10,4 & 6 & 24 \\
\hline $30-34$ & 54 & 17,08 & 4 & 16 \\
\hline $35-39$ & 41 & 12,9 & 6 & 24 \\
\hline $40-44$ & 46 & 14,5 & 6 & 24 \\
\hline $45-49$ & 35 & 11,07 & 1 & 4 \\
\hline $50-54$ & 24 & 7,59 & 1 & 4 \\
\hline $55-59$ & 17 & 5,37 & - & - \\
\hline $60-64$ & 12 & 3,79 & 1 & 4 \\
\hline $65-69$ & 5 & 1,58 & - & - \\
\hline $70-74$ & 2 & 0,6 & - & - \\
\hline DESCONOCIDOS & 47 & 14,8 & 1 & 4 \\
\hline TOTALES & 316 & & 25 & \\
\hline
\end{tabular}

FUENTE: A.M.CO.,

Expedientes de elecciones municipales. Censo electoral, BOP, Prensa. Elaboración propia.

Como puede apreciarse en el cuadro número 1, los alcaldes objeto de nuestro estudio están encuadrados entre los veinticinco y cuarenta y cuatro años. Si consideramos que la esperanza de vida de un español nacido en 1900 era de cuarenta años, se podían considerar como privilegiados.

${ }^{30} \mathrm{M} \cdot{ }^{a} \mathrm{~S}$. FERNÁNDEZ LÓPEZ «Antonio Cruz Conde, el calita azul. Su paso por la alcaldia cordobesa», en Actas del III Congreso de Historia de Andalucía, Córdoba, 2003, III, pp. 183 y ss. 
Al tratarse de cargos locales estrechamente vinculados al vecindario, era lógico que la inmensa mayoría nacieran en la ciudad de Góngora y Lucano. No obstante, hay excepciones el valenciano Jaime Aparicio Marín y Tejón Marín, oriundo de Málaga.

El análisis de la titulación académica de los concejales cordobeses refrenda la opinión más difundida acerca de la actividad profesional de los políticos de las Restauración. Hay un predominio absoluto del título de licenciado en Derecho. Sesenta y tres fueron los ediles que cursaron esta titulación. De ellos, doce fueron alcaldes. Este grupo estaba integrado por Barrios Rejano, Belmonte Cárdenas, Conde Jiménez ${ }^{31}$, Enriquez Barrios, García Lovera $^{32}$, etc. Le sigue la licenciatura de Mediciria —-como el liberal Juan Giménez González-, Química y Veterinaria y, más de lejos las enseñanzas técnicas con varios ediles peritos agrícolas - José Sanz Noguer-. Pese a lo expuesto, sin ninguna duda, el contingente más importante de regidores se reclutó en la Facultad de Derecho.

En lo referente a la actividad profesional de los concejales encabezan el ranking los propietarios, generalmente dueños o arrendatarios de fincas rústicas: Fernando Vienlant y Villanueva, marqués de Gelo, y el hermano del insigne conde de Leyva, Tomás Conde y Luque. Asimismo, tenemos un industrial, Eduardo Alvarez de los Ángeles.

31 «Rafael Conde Jiménez ejerció como concejal del Ayuntamiento de Córdoba entre 1903 y 1907, siendo alcalde durante el bienio 1904-1905. De aquí saltó a las Cortes convirtiéndose en diputado por Cabra entre 1905 y 1907 . También fue presidente de la Diputación Provincial cordobesa, gobernador civil de las provincias de Cáceres y jaén y, para culminar su cursus honorum, elegido senador por Córdoba en las elecciones de 1919 y $1921 \%$. J. PONCE ALBERCA, Del poder y sus hombres. José Cruz Conde (1878-1939). Semblanzas biográficas y perfiles ideológicos..., p. 31.

${ }^{32}$ "Comenzó en la Universidad de Sevilla los estudios de la ciencia del Derecho, en cuyo centro distinguióse como alumno sobresaliente. Fue uno de los pocos que obtuvieron en la Universidad hispalense el grado de Bachiller en Derecho Civil y Canónico, con asistencia de más de setenta doctores, mereciendo la calificación de nemine discrepante... Durante el año 1843 dirigió en esta su ciudad natal del Kalifato la revista literarias nominada 'El Vergel', además de colaborar en otros periódicos; durante 'este año confeccionó la comedia titulada 'Corte de Cuentos', amoldadas a la exigencia de al época [....] Recibió la investidura de Jurisconsulto en la Universidad Central en 1848». F. GonZÁlez y SAEZ, Biografías de cordobeses contemporáneos, Córdoba, 1895, pp. 5-6. 


\section{Cuadro 2 \\ Clasificación profesional}

\begin{tabular}{|c|c|c|c|c|c|}
\hline \multicolumn{2}{|c|}{ Actividad } & $\begin{array}{l}\text { Núm. } \\
\text { Concejales }\end{array}$ & $\%$ & $\begin{array}{l}\text { Núm. } \\
\text { Alcaldes }\end{array}$ & $\%$ \\
\hline \multicolumn{6}{|c|}{ Profesionales liberales: } \\
\hline Juristas & Abogados & 63 & 62,9 & 12 & 48 \\
\hline \multirow[t]{2}{*}{ Docentes: } & $\begin{array}{l}\text { Catedrático de } \\
\text { Instituto }\end{array}$ & 3 & 0,9 & - & - \\
\hline & $\begin{array}{l}\text { Catedrático de } \\
\text { Universidad }\end{array}$ & 3 & 0,9 & - & - \\
\hline \multirow[t]{2}{*}{ Sanidad: } & Médico & 6 & 1,8 & 1 & 4 \\
\hline & Farmacéutico & 9 & 2,8 & 1 & 4 \\
\hline \multirow{3}{*}{ Técnicos } & Arquitecto & 2 & 0,6 & - & - \\
\hline & Agrimensor & 4 & 1,2 & - & - \\
\hline & Perito agrícola & 3 & 0,9 & 1 & 4 \\
\hline Tipógrafos: & & 1 & 0,3 & - & - \\
\hline $\begin{array}{c}\text { Corresponsal } \\
\text { de prensa }\end{array}$ & & 1 & 0,3 & - & - \\
\hline Estudiante: & & 1 & 0,3 & - & - \\
\hline \multirow{7}{*}{$\begin{array}{l}\text { Empleos } \\
\text { varios: }\end{array}$} & Banca & 2 & 0,6 & - & - \\
\hline & Administrador & 1 & 0,3 & - & - \\
\hline & Empleado & 16 & 5,06 & - & - \\
\hline & Comerciante & 27 & 8,5 & 2 & 8 \\
\hline & Escribiente & 1 & 0,3 & - & - \\
\hline & Representante & 4 & 1,26 & - & - \\
\hline & Marinero & 1 & 0,3 & - & - \\
\hline \multirow{2}{*}{$\begin{array}{c}\text { Obreros } \\
\text { Manuales }\end{array}$} & Obreros & 16 & 5,06 & - & - \\
\hline & Platería & 16 & 5,06 & - & - \\
\hline \multirow{2}{*}{$\begin{array}{l}\text { Trabajadores } \\
\text { del campo: }\end{array}$} & Jornaleros & 1 & 0,3 & - & - \\
\hline & Labrador & 3 & 0,9 & - & - \\
\hline \multirow{3}{*}{ Propietarios: } & Gran Propietarios & 5 & 1,58 & 2 & 8 \\
\hline & Propietarios & 69 & 21,8 & 6 & 24 \\
\hline & $\begin{array}{l}\text { Propietarios } \\
\text { Industriales }\end{array}$ & 18 & 5,6 & 1 & 4 \\
\hline Desconocidos: & & 40 & 12,6 & - & \\
\hline Totales & & 316 & & 25 & \\
\hline
\end{tabular}

Fuente: A.M.CO., Expedientes de elecciones municipales.

Censo Electoral BOP, prensa. Elaboración propia 
Entre 1900-1923, la nota quizás más destacada fue el hecho de que se sucedieran 17 alcaldes. La media de permanencia en el cargo no llega a los dos años. Si a esto le añadimos que de acuerdo con la legislación vigente, el presidente de la corporación municipal tendía a ser un delegado menor de turno, carente de un marco competencial que le permitiera llevar a cabo una acción de gobierno propia, entenderemos la ausencia de programas electorales. Córdoba era una ciudad donde estaban fuertemente arraigadas las prácticas caciquiles. Por ello, cuando las divisiones internas empezaron a descomponer los partidos de turno, la ciudad se vio seriamente afectada por la crispación política convirtiéndose en un excelente observatorio para contemplar la descomposición del sistema oligárquico de la Restauración. Esto puede corroborarse con las numerosas consultas electorales a fines del período - 1918, 1919, 1920 y 1923 - que «no sirvieron, por ejemplo de marrullería dado desde comités y jefatura, como pedagogía política para el ciudadano cordobés» ${ }^{33}$.

En puridad, todos o casi todos los elementos analizados hasta aquí como constitutivos de la condición de concejal adquieren mayor importancia al analizar el cursus honorum de los alcaldes. 


\section{Cuadro 3 \\ Los primeros ediles cordobeses agrupados por orden cronológico de acceso a la alcaldía}

\begin{tabular}{|c|c|c|c|c|}
\hline NOMBRE & NACIMIENTO & PROFESIÓN & ADSCRIPCIÓN & MANDATO \\
\hline CONDE Y LUQUE, Tomás & Córdoba, 1833 & G. Propietario & Conservador & $\begin{array}{l}* 2 / 01 / 1875-7 / 01 / 1876 \\
* 11 / 08 / 1876-/ 04 / 1877\end{array}$ \\
\hline $\begin{array}{l}\text { VIENLANT Y VILLANUEVA, Fernando } \\
\text { (marqués de Gelo) }\end{array}$ & Córdoba, 1849 & G. Propietario & Conservador & $\begin{array}{l}* 13 / 04 / 1877-13 / 05 / 1878 \\
* 7 / 01 / 1876-7 / 08 / 1876\end{array}$ \\
\hline $\begin{array}{l}\text { BELMONTE Y CARDENAS, Bartolomé } \\
\text { (marqués de Sta. Rosa) }\end{array}$ & Córdoba, 1842 & Abogado & Conservador & $\begin{array}{l}17 / 05 / 1878-14 / 03 / 1881 \\
* 8 / 02 / 1884-5 / 06 / 1884 \\
* 29 / 12 / 1884-22 / 02 / 1886 \\
\end{array}$ \\
\hline RODRIGUEZ SÁNCHEZ, Juan & Córdoba, 1828 & Abogado & Liberal & $\begin{array}{l}* 21 / 03 / 1881-1 / 07 / 1881 \\
* 26 / 02 / 1886-29 / 12 / 1889\end{array}$ \\
\hline $\begin{array}{l}\text { AGUAYO Y FERNÁNDEZZ DE MESA, } \\
\text { Mariano }\end{array}$ & 18563 & Propietario & Conservador & ${ }^{*} 29 / 12 / 1890-26 / 01 / 1891$ \\
\hline $\begin{array}{l}\text { ARROSPIDE Y MARIN , F. De Paula } \\
\text { (marqués de Boil) }\end{array}$ & 1849 & G. Propietario & Conservador & $\begin{array}{l}* 1 / 07 / 1881-1 / 07 / 1883 \\
* \quad 5 / 07 / 1883-12 / 1883\end{array}$ \\
\hline GARCIA LOVERA, Rafael & Córdoba, 1825 & Abogado & Liberal & ${ }^{*} 29 / 01 / 1884-4 / 02 / 1884$ \\
\hline REY GORRINDO, Pedro & 1854 & Abogado & Conservador & ${ }^{*} 1 / 01 / 1890-12 / 12 / 1890^{34}$ \\
\hline TEJÓN Y MARÍN, Juan & Málaga, 1860 & Comerciante & Conservador & $* 8 / 04 / 1891-30 / 01 / 1893$ \\
\hline GIMÉNEZ GONZÁlEZ, Julián & 1845 & Médico & Liberal & ${ }^{*} 30 / 01 / 1893-4 / 10 / 1893^{35}$ \\
\hline APARICIO MARINN, Jaime & Valencia, 1843 & Propietario & Liberal & $\begin{array}{l}* 16 / 10 / 1893-8 / 04 / 1895 \\
* 17 / 11 / 1897-30 / 06 / 1898 \\
* 4 / 07 / 1898-26 / 03 / 1899 \\
* 25 / 06 / 1901-29 / 01 / 1903^{36} \\
\end{array}$ \\
\hline ARIZA VICTOR, Antonio & 1842 & Abogado & Conservador & ${ }^{*} 10 / 04 / 1895-26 / 12 / 1895$ \\
\hline ÁlVAREZ DE LOS ÁNGELES, Eduardo & 1849 & Fabricante & Conservador & $\begin{array}{l}* 2 / 01 / 1896-30 / 12 / 1896 \\
* 4 / 01 / 1897-25 / 06 / 1897\end{array}$ \\
\hline MOLINA FERNÁNDEZ, José Ma & 1865 & Abogado & Conservador & $* 1 / 07 / 1897 \cdot 17 / 11 / 1897^{37}$ \\
\hline VELASCO NAVARRO, Juan L. & 1858 & Propietario & Conservador & $* 27 / 03 / 1899-1 / 06 / 1901$ \\
\hline $\begin{array}{l}\text { PINEDA DE LAS INFANTASY } \\
\text { CASTILLEO, Antonio (conde de infantas) }\end{array}$ & 1868 & Propietario & Conservador & $\begin{array}{l}* 1 / 03 / 1903-1 / 01 / 1904 \\
* 4 / 03 / 1907-14 / 06 / 1909\end{array}$ \\
\hline CONDE JMÉNEZ, Rafael & 1865 & Abogado & Conservador & $* 4 / 01 / 1904-30 / 12 / 1905$ \\
\hline GARCIA MARTÍNEZ, José & 1850 & Formacéutico & Liberal & $\begin{array}{l}* 8 / 01 / 1906-4 / 03 / 1907^{38} \\
* 12 / 11 / 1909-1 / 01 / 1912\end{array}$ \\
\hline
\end{tabular}

${ }^{34}$ A.M.CO, Actas Capitulares, 1890, sección 13.03.01, L-0424.

${ }^{35}$ Tras la polémica suscitada por el traslado de la capitalidad militar a Sevilla, el alcalde presentó su dimisión.

${ }^{36}$ Al ser nombrado senador presentó su dimisión. A.M.CO., Expedientes de elecciones municipales de 1903, sección 11.04.01, C. 1002.

${ }^{37}$ Presentó su dimisión. A.M.CO., Actas capitulares de 1897, sección 13.03.01, L-0438, folios 538 y ss.

${ }^{38}$ El 4 de marzo de 1907 renunció a la alcaldía. Para sucederle fue designado Pineda de las Infantas. A.M.CO., Actas capitulares de 1907, sección 13.03.01, L-0453, folio 46. 


\begin{tabular}{|c|c|c|c|c|}
\hline JIMÉNEZ AMLO, Rafad & 1865 & Abogado & Conservador & ${ }^{*} 17 / 06 / 1909^{39}-8 / 11 / 1909^{40}$ \\
\hline MUÑOZ PÉREZ, Salvador & 1876 & Abogado & Liberal & $\begin{array}{l}{ }^{*} 1 / 01 / 1912-29 / 11 / 1913^{41} \\
{ }^{*} 1 / 01 / 1916^{22}-27 / 06 / 1917\end{array}$ \\
\hline ENRIQUEZ BARRIOS, Manuel & 1877 & Abogado & Conservador & * 29/11/1913-1/01/1916 \\
\hline SANZ NOGUER, Jose & 1883 & Perito Agricola & Liberd & $\begin{array}{l}* / 12 / 1917-31 / 12 / 1917 \\
* 1 / 01 / 1918-1 / 04 / 1920\end{array}$ \\
\hline $\begin{array}{l}\text { FERNÁNDEZ DE MESA Y PORRAS, } \\
\text { Francisco }\end{array}$ & 1879 & Abogado & Conservador & $* 3 / 04 / 1920-26 / 06 / 1921$ \\
\hline BARRIOS REJANO, Sebastián & 1871 & Abogado & Conservador & $\begin{array}{l}{ }^{*} 26 / 06 / 1921-28 / 03 / 1922 \\
{ }^{*} 1 / 04 / 1922-17 / 01 / 1923\end{array}$ \\
\hline $\begin{array}{l}\text { LOPEZ Y GONZÁlEZ DE CANALES, } \\
\text { Patricio }\end{array}$ & - & & Conservador & ${ }^{*} 17 / 01 / 1923-8 / 11 / 1923$ \\
\hline CARRILLO PÉREZ, José & 1850 & & Conservador & ${ }^{*} 27 / 06 / 1917-6 / 12 / 1917$ \\
\hline
\end{tabular}

FUENTE: A.M.CO., EXPEDIENTES DE ELECCIONES MUNICIPALES. CENSO ELECTORAL. BOP, PRENSA. ELABORACIÓN PROPIA

${ }^{39}$ «Se dio cuenta de un oficio del Gobernador Civil de la provincia trasladándose de Real Orden expedida por el Ministerio de al Gobernación con fecha del 14 del actual por la que se nombra alcalde presidente de este Excelentísimo Ayuntamiento al Sr. Jiménez Amigo, concejal del mismo, por renuncia de él que ha venido desempeñando dicho cargo». A.M.CO., Actas Capitulares de 1909, sección 13.03.01, L0456,17 de junio de 1909 , folios 50 y 51 .

${ }^{40}$ «Por Real Orden del Ministerio de la Gobernación se cesó en el cargo de Alcalde presidente a Rafael Jiménez Amigo nombrándose para ocupar al cargo a José García Martínez». A.M.CO., Actas Capitulares de 1909, sección 13.03.01, L-0457, 12 de noviembre de 1909, folios 2 y 3.

${ }^{41}$ «Por disposición del Sr. Gobernador Civil, presidente, leyerónse del Reales ordenes expedidas con fecha 28 del que rige, por la primera de las cuales se admite la renuncia presentada por D. Salvador Muñoz para continuar desempeñando el cargo de alcalde presidente para que fue nombrado pro R.O. de 26 de diciembre de 1911 y por la segunda se confiere el expresado cargo a D. Manuel Enriquez Barrios". A.M.CO., Actas Capitulares de 1913, sección 13.03.01, L-0463, 29 de noviembre de 1913, folio 184.

${ }^{42}$ Tras leerse el telegrama de Agustín de la Serna, Gobernador Civil de al provincia, donde se informaba de la designación por Real Orden de Muñoz Pérez para desempeñar el cargo de Alcalde, Rafael Gutiérrez Villegas, en nombre de la minoría republicana expuso «el descontento que le producía que el Jefe del Estado hubiera conferido el nombramiento del Alcalde, cuando el Sr. Muñoz por los relevantes merecimientos que le distinguen, hubiera podido obtener ese cargo por el voto de la corporación". A.M.CO., Actas Capitulares de 1916, sección 13.03.01, L-0467, 1 ce enero de 1916, folios 51-57.

${ }^{43}$ El 8 de noviembre de 1923 los ediles reunidos en el consistorio cordobés coincidieron en que, en aquellos difíciles momentos para la ciudad, quién mejor podía defender los intereses de la comunidad era el conde de las Infantas. "Se procedió a la votación en la forma prevenida en el art. 54 de la Ley Orgánica, depositándose en la urna destinada al efecto la papeleta de cada uno de los señores concejales presentes. Verificado el escrutinio resultó: d. Antonio Pineda, con 26 votos y uno en blanco». A.M.CO., Actas Capitulares de 1923, L-0482, 8 de noviembre de 1923, folio 64 . 
Como ha quedado expuesto a lo largo de estas páginas, en la capital cordobesa se aprecia un apoliticismo de la clase media, facilitándose, con ello, la permanencia del status quo canovista. Esa docilidad hizo que el caciquismo encontrara en la ciudad de la Mezquita un ambiente propicio para su manipulación electoral. Con los últimos años de la Restauración, Córdoba se convertirá en un excelente observatorio para contemplar la descomposición del sistema caciquil y oligárquico del que la situación política cordobesa había sido hasta entonces un modelo impar. Naturalmente, los intereses de la ciudad no ganaron nada con esta crispación política. Como nos apunta Cuenca Toribio, esta urbe contaba "con una masa popular inclinada, en su resortes últimos, hacia las formas tradicionales y muy encuadrada en los trances decisivos por los poderes fácticos representados por la Iglesia y la nobleza, cabría sostener el conservadurismo del talante político de la ciudad» ${ }^{44}$. De hecho, ese laboratorio político al que nos referíamos más arriba pudo verse en el discurso pronunciado por Alfonso XIII, el 23 de mayo de 1921 , en el Círculo de la Amistad ${ }^{45}$, en el cual se anunciaba subliminalmente la primera dictadura española del siglo XX.

\section{BIBLIOGRAFÍA}

Aguilar Gavilán, E., Historia de Córdoba, Madrid, 1995.

Arjona CaStro, A., La población cordobesa en el siglo XIX. Sanidad y crisis demográfica en la Córdoba decimonónica, Córdoba, 1979.

artola Gallego, M., Elecciones y Partidos Políticos, Madrid, 1977.

BERNARDO DE ARES, J.M.; El poder municipal y la organización política de la sociedad. Algunas lecciones del pasado, Córdoba, 1998

Comellas García-Llera, J.L., El sistema político de Cánovas, Madrid, 1961.

- La Restauración como experiencia histórica, Sevilla, 1977.

CuENCA TORIBIO, J.M., Andalucía, una introducción histórica, Córdoba, 1979.

- Andalucía. Historia de un pueblo (... a.C.-1984), Madrid, 1984.

- Pueblos y gentes de Córdoba, Córdoba, 1989.

- Historia de Córdoba, Córdoba, 1993.

${ }^{44}$ Historia de Córdoba, Córdoba, 2002, 2.. ed., p. 151.

${ }^{45}$ El Círculo de la Amistad y Liceo Artístico de Córdoba era al comienzo del siglo XX el Club más importante de la localidad y, por ende, de la provincia. En este caso es el centro de relación entre élites, de creación y reforzamiento de redes clientelares, con finalidad política y económica. Este organismo ha sido magníficamente estudiado por Ramirez Ruiz. En su opinión, el casino cordobés hay que estudiarlo «no como partes de la estructura de poder que sustenta la imposición del sistema político, sino desde una perspectiva integradora, viéndolos como unas instituciones asociativas representativas de un tipo de sociedad a caballo entre el liberalismo del XIX y las tendencias democráticas y totalitarios del siglo XX, donde durante mucho tiempo se dieron cita los oligarcas más rancios, pero también, las porciones más ilustradas de las sociedades municipales, atentas a las corrientes culturales, técnicas e ideológicas de su tiempo", "El Casino Círculo de la Amistad de Córdoba, 1902-1931: una institución para una época", en Actas del III Congreso de Historia de Andalucía, Córdoba, 2003, IV, p. 566. 
Cuenca ToRibio, J.M. y MiRanda García, S., «Sociología ministerial de la Restauración, (18751902)", en Revista de Estudios Políticos, 78 (1992).

Domínguez Ortiz, A., Córdoba: apuntes para su historia, Córdoba, 1981.

Fernández Almagro, M., Historia política de la España contemporánea, 3 tomos, Madrid, 1972-1974.

FERNÁNDEZ LÓPEZ, M M S., «Antonio Cruz Conde, el califa azul. Su paso por la alcaldía cordobesa», en Actas del III Congreso de Historia de Andalucía, Córdoba, 2003, III, pp. 183 y ss.

Forner, S., (coord.), Democracia, elecciones y modernización de Europa. Siglos XIX y XX, Madrid, 1997.

FreIXA Y RABASO, E., Elecciones por Sufragio universal de diputados provinciales y concejales, Córdoba, 1881.

GonZÁlez Y SAENZ, F., Biografías de cordobeses contemporáneos, Córdoba, 1895.

Macias PICAVEA, R., El problema nacional, Madrid, 1899.

Miranda Garcia, S. y López Mora, F., "Clasificación socioprofesional de Córdoba en el siglo XIX: metodología y primeros resultados", en Actas del /l Congreso de Historia de Andalucía, Córdoba, 1996, I, pp. 147-151.

Montis Romero, R., Notas cordobesas (Recuerdos del pasado), VIl, Córdoba, 1989.

MoRILLA CRITZ, J., «El ferrocarril de Córdoba a la cuenca hullera de Espiel y Bélmez (1852-1880», en Revista de Historia Económica, 1 (1984).

Palacios Bañuelos, L., Historia de Córdoba. La etapa contemporánea, Córdoba, 1990.

Pérez Bustamante, R., Historia de las instituciones públicas de España, Madrid, 1995.

Ponce Alberca, J., Del poder y sus hombres. José Cruz Conde (1878-1939). Semblanzas biográficas y perfiles ideológicos de una figura política andaluza, Córdoba, 2001.

POSADA, A., Evolución legislativa del régimen local en España, 1912-1909, Madrid, 1982.

- El régimen municipal de la ciudad moderna y bosquejo del Régimen local en España, Francia, Inglaterra, Estados Alemanes y Estados Unidos, Madrid, 1916.

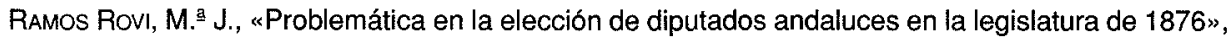
en Actas del II Congreso de Historia de Andalucia. Andalucía Contemporánea, Córdoba, 1996, I, pp. 403-412.

- «Elecciones municipales en Córdoba (1875-1885)», en Ámbitos. Revista de Ciencias Sociales y Humanidades de Córdoba, 2(1999), pp. 98 y ss.

- "La elección de diputados a Cortes en la Córdoba de Alfonso XIl», en Actas de las IV Jornadas Niceto Alcalá-Zamora y su época, Córdoba, 1999, pp. 141-160.

- "La Constitución de 1876 a través de los discursos parlamentarios" ", en Revista de Historia Contemporánea, 9-10 (1999-2000), pp. 85-100.

ROMANELLI, R., «Sistemas electorales y estructuras sociales. El siglo XIX europeo», en FoRNER, S., (coord.), Democracia, elecciones y modernización en Europa. Siglos XIX y XX, Madrid, 1997.

Ramírez Ruiz, R., «El Casino Círculo de la Amistad de Córdoba, 1902-1931: una institución para una época", en Actas del III Congreso de Historia de Andalucía, Córdoba, 2003, IV, pp. 566 y ss.

TOMÁs DE VILLAROYA, J., El sistema político del Estatuto Real, Madrid, 1968.

TUSELL Gómez, J., Oligarquía y caciquismo en Andalucía, (1890-1923), Barcelona, 1976.

- La reforma de la Administración local en España (1900-1936), Madrid, 1973.

ZanCADA, P., Las elecciones legislativas en España, Madrid, 1914. 